\title{
In celebration of 30 years of Structural Chemistry: launching a series of prefatory reviews
}

\section{Istvan Hargittai ${ }^{1}$}

Published online: 25 April 2019

(C) Springer Science+Business Media, LLC, part of Springer Nature 2019

The idea of launching Structural Chemistry (nowadays often referred to as "STUC") was born in 1988 in conversations among Arthur Greenberg, Joel Liebman, Magdolna Hargittai, and myself. The main reason why we wanted to have a new periodical was the realization of the need of an international forum of structural chemistry of broad scope and rigorous reviewing. Art and I became Editors, Joel, Consulting Editor, and Magdi (short for Magdolna), Book Reviews Editor. The new journal started publication in 1990. There had been changes in publisher until the journal finally anchored with Springer Nature. After a few years, when Art had an appointment to a high administrative position at his university, he withdrew from active editing and has continued as a member of the Editorial Board. Jerzy Leszynski joined as Editor and now for many years, Jerzy and I have worked together in a pleasant and fruitful interaction.

Istvan Hargittai

stuceditor@gmail.com

1 Department of Inorganic and Analytical Chemistry, Budapest University of Technology and Economics, PO Box 91,

Budapest 1521, Hungary
As Structural Chemistry has entered its 30th year of publication, we have decided to initiate a series of prefatory reviews that are planned to appear in the order of their arrival (following review and revision if needed). These reviews will be appearing under the heading REVIEWS at the beginning of the journal issues; starting with the present issue. One of our colleagues has called this arrangement — most appropriatelycreating a "delocalized" special issue. Upon the completion of the series, some time in 2020, the plan is to fuse these reviews in a joint set of papers.

Publisher's note Springer Nature remains neutral with regard to jurisdictional claims in published maps and institutional affiliations. 